\title{
Toona ciliata genotype selection with the use of individual BLUP with repeated measures
}

\author{
Rulfe Tavares Ferreira ${ }^{1}$, Alexandre Pio Viana ${ }^{*}$, Déborah Guerra Barroso², Marcos Deon Vilela de Resende ${ }^{3}$, Antônio Teixeira do \\ Amaral Júnior ${ }^{1}$
}

\author{
${ }^{1}$ UENF/CCTA - Lab. de Melhoramento Genético Vegetal - \\ 28015-610 - Campos dos Goytacazes, RJ - Brasil. \\ 2UENF/CCTA - Lab. de Fitotecnia - 28015-610 - \\ Campos dos Goytacazes, RJ - Brasil. \\ 3UFV - Depto. de Engenharia Florestal - 36570-000 - \\ Viçosa, MG - Brasil. \\ *Corresponding author < pirapora@uenf.br>
}

Edited by: Antonio Costa de Oliveira

\begin{abstract}
The increasing demand for raw material for multiple uses of forest products and byproducts has attracted the interest for fast growing species, such as the Australian Cedar (Toona ciliata), which presents high productive and economic potential. This study aimed at estimating genotypic parameters and values for the species through the use of the BLUP procedure, at individual level, with repeated measures, by means of the conventional evaluation procedures and the introduction of innovative digitalization of the measurements by digital camera with the images provided by the Imagej software system. The main objective is to subsidize the beginning of a breeding program for the species. The assays were carried out in private properties, in plantations located in the state of Rio de Janeiro, Brazil. The results generated by three evaluations revealed that the image digital analysis is adequate to quantify characteristics of Toona ciliata. It is also an effective and accurate alternative to minimize the costs of data collection in evaluations with the species. There was high accuracy for the characters plant height, diameter at breast height and cylindrical volume. Out of the 90 genotypes evaluated, 38 expressed genotypic values predicted for the diameter at breast height higher than the general average of this character, 33 for the cylindrical volume and 49 for height, allowing gains of up to $24.9 \%$ in average for cylindrical volume. The method of mixed models (REML/BLUP) applied via the SELEGEN software system, using the BLUP procedure at individual level and repeated measures in each individual proved to be adequate to estimate the genetic parameters and predict genotypic values in situations of unbalanced data. Therefore, it is very useful and practical for Toona ciliata genetic breeding programs.

Keywords: Australian Cedar, mixed models
\end{abstract}

Received November 25, 2010

Accepted January 10, 2012
Padilha et al. (2003) and Farias Neto (2002) have emphasized the importance of the repeatability models (parameter associated to the phenotypic correlation among repeated measures in the same individual) for the genetic evaluation of some perennial species, such as erva-mate (Ilex paraguariensis St.Hil), and fast growing forest species. The genetic evaluation involving individuals of these species is based on models that consider both the effect of the permanent environment and the mentioned repeatability.

In spite of the potential of the BLUP technique, the quantifications of biometric characteristics in forest species of interest for the market have been currently estimated by conventional procedures, which demand more time and resource. Besides, some characteristics are difficult to be accessed and highly susceptible to errors of inference, such as the canopy diameter. An alternative for this is the use of non-conventional procedures, such as that proposed in this study, which performs the measurement of the desired characteristics in individuals of populations by means of the analysis of images with the use of digital camera with photographical documentation via the Imagej software system. Therefore, this study aimed at estimating parameters and genotype values by the BLUP procedure at the individual level, in populations of Australian Cedars, using several individuals and repeated measures, estimated by conventional procedures of measurement and by digitalization of images, aiming at assessing the efficiency of the non- 
conventional estimates in Toona ciliata and subsidize the start of a breeding program with the species.

\section{Materials and Methods}

The assays were carried out in commercial plantations of Australian Cedar in three locations: i) Triunfo,

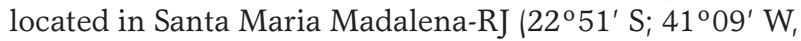
$118 \mathrm{~m}$ a.s.1; ii) Alto Imbé, located in Santa Maria Madale-

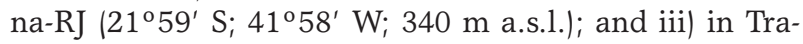
jano de Moraes-RJ (22 $07^{\prime} \mathrm{S}$; $42^{\circ} 13^{\prime} \mathrm{W}$; $660 \mathrm{~m}$ a.s.l).

The plantations were implanted in the second half of 2005 , in the spacing of $3 \times 2 \mathrm{~m}$, with seedlings produced by seminal via. The seeds used in Triunfo were from the state of Espírito Santo and those of Alto Imbé and Trajano, from plantations of Viçosa-MG. Thirty individuals were randomly preselected in each plantation, and three measurements were performed, with 6-month intervals between them. After completion, the average was used for all analyses.

\section{Phenotyping via digital and conventional analysis}

In this study, in which a new methodology was used for variable measurement by means of a digital camera, the averages of the digitalized images were compared, and then measurements were performed of the diameter at breast height $(\mathrm{DBH})$ and stem diameter (SD) in an image, and height $(\mathrm{H})$ in another image, with the use of the Imagej software system, in comparison to the manual collection using Suta to measure the diameter at breast height (DBH) and stem diameter (SD), and graduated scale to measure height $(\mathrm{H})$, in the same population.

The preselected plants were evaluated as for the following characteristics: plant height $(\mathrm{H})$, diameter at breast height $(\mathrm{DBH})$, cylindrical volume $(\mathrm{CV})$, stem diameter (SD), distance between nodes (Internodes) and canopy diameter (CD). Those were estimated by two procedures: i) measurement using Suta and graduated scale; and the diameter at breast height (DBH) was measured: in centimeters $(\mathrm{cm})$, at $1.3 \mathrm{~m}$ of the height of the trunk base. The cylindrical volume (CV): was indirectly estimated, through the use of the equation $(\varpi / 4) \times \mathrm{DBH}^{2} . \mathrm{H}$, using the measurements of the characteristics mentioned in the equation, which had been previously achieved. The stem diameter (SD): in centimeters $(\mathrm{cm})$, was estimated at the base of the plants. The distance between nodes (Internodes): in centimeters ( $\mathrm{cm})$, was achieved through the weighted average of the distances among the nodes immediately superior to $1.30 \mathrm{~m}$ of height of the base of the trunk. The diameter of the canopy (CD): in centimeters $(\mathrm{cm})$, was quantified at the height of the branches, and the image of the base of the plant was achieved focusing the canopy and ii) measuring the desired characteristics, through the analysis of the images of each individual from two different positions by the Imagej software system. The images were achieved with the use of a digital camera, with resolution of 4.1 mega pixels.
The data achieved by the conventional methodology of measurement and by image digital analysis were subjected to the test of homogeneity of variances (F test) and t-test for two independent samples, to assess the validation of the data achieved by means of digitalized image.

In this aspect, the study aimed at investigating if the digital analysis methodology differed from the manual data collection methodology, which is traditionally used. For such, the Student t-test was applied to contrast the differences among population averages, considering the paired data, that is, for the same population, testing the digital analysis of the images and the manual data collection.

\section{Genetic parameter estimates}

The genetic values were estimated with the use of the Selegen-REML software system through the individual BLUP procedure with repeated measures for the characteristics plant height $(\mathrm{H})$, diameter at breast height $(\mathrm{DBH})$, cylindrical volume $(\mathrm{CV})$, stem diameter (SD), distance between nodes (Internodes) and canopy diameter (CD).

The prediction of the genetic values followed the statistical model, in the context of the mixed linear models, presented as follows: $y=X m+Z g+W i+e$, in which: $y$ is the data vector, $m$ is the vector of the effects of the local combinations and measurements (assumed as fixed) added to the general mean, $g$ is the vector of the genotypic effects added to the vector of the effects of permanent environment (assumed as random), $i$ is the vector of the effects of the genotype $\times$ measurement interaction and, $e$ is the vector of errors or residues (random). The capital letters represent the incidence matrices for the mentioned effects. The vector $m$ comprises all the measurements in all the locations and adjusts simultaneously, for the effects of locations, measurement and location $\times$ measurement interaction.

The equations of mixed models to estimate the fixed effects and predict the random effects by the BLUP procedure, presented by Resende (2000) are given by:

$$
\left[\begin{array}{l}
\hat{m} \\
\hat{g} \\
\hat{i}
\end{array}\right]=\left[\begin{array}{ccc}
X^{\prime} X & X^{\prime} Z & X^{\prime} W \\
Z^{\prime} X & Z^{\prime} Z+I^{-1} \lambda_{1} & Z^{\prime} W \\
W^{\prime} X & W^{\prime} Z & W^{\prime} W+I \lambda_{2}
\end{array}\right]^{-1}\left[\begin{array}{l}
X^{\prime} y \\
Z^{\prime} y \\
W^{\prime} y
\end{array}\right],
$$

in which:

$$
\begin{aligned}
& \lambda_{1}=\frac{\sigma_{e}^{2}}{\sigma_{g}^{2}}=\frac{(1-r)}{r} ; \\
& \lambda_{2}=\frac{\sigma_{e}^{2}}{\sigma_{i}^{2}}=\frac{(1-r)}{c^{2} g m} ;
\end{aligned}
$$

To achieve the variance components, the following

Vf: permanent phenotypic variance. Vfp $=\frac{m \hat{\rho}}{1+(m-1) \hat{\rho}}$ 
Vgm: variance of the genotype $\times$ measurement interaction. $V g m=\frac{V g *}{V g x \cdot V g y}$

Ve: temporary residual variance.

Vf: individual phenotypic variance. $V f=V g+V e t$

r: repeatability of individual plants. $r=\frac{V g}{V f}$

$\mathrm{c}_{2} \mathrm{gm}=\mathrm{C}_{21}$ : coefficient of determination of the effects of the genotype $\times$ measurement interaction. $c^{2} g m=\frac{\sum\left(Y_{i}^{h}-\bar{Y}_{i}\right)^{2}}{\sum\left(Y_{i}-\bar{Y}_{i}\right)^{2}}$ rgmed: genotypic correlation through measurements.

rm: repeatability of the average of genotypes (determina-

tion). $r m=\frac{m \cdot r}{1+(m-1) \hat{\rho}}$

Acgen: accuracy in the selection of genotypes. Acgen $=\left[\frac{m \cdot r}{1+(m-1) \hat{\rho}}\right]^{\frac{1}{2}}$

\section{Results and Discussion}

The results achieved for the characteristics diameter at breast height (DBH), stem diameter (SD) and plant height $(\mathrm{H})$ are shown in Table 1 . The averages were statistically equal by the $\mathrm{t}$ test in the comparison among averages for both methodologies analyzed. This fact guarantees that the results achieved for the variables

Table 1 - Averages of the digital and conventional analyses referring to the diameter at breast height (DBH), stem diameter (SD) and plant height $(H)$. The same letters in the column do not differ ( $t$ " test, $p<0.05)$.

\begin{tabular}{lccllllll}
\hline \multirow{2}{*}{ Method } & \multicolumn{2}{c}{ DBH } & & \multicolumn{2}{c}{ SD } & & \multicolumn{2}{c}{$H$} \\
\cline { 2 - 3 } \cline { 7 - 8 } & Average & $\sigma^{2}$ & & average & $\sigma^{2}$ & & average & $\sigma^{2}$ \\
\hline Manual & $14.02 \mathrm{a}$ & $7.44 \mathrm{a}$ & & $18.12 \mathrm{a}$ & $9.72 \mathrm{a}$ & & $12.00 \mathrm{a}$ & $1.16 \mathrm{a}$ \\
Digital & $13.80 \mathrm{a}$ & $7.04 \mathrm{a}$ & & $17.20 \mathrm{a}$ & $7.81 \mathrm{a}$ & & $11.90 \mathrm{a}$ & $1.21 \mathrm{a}$ \\
\hline
\end{tabular}

mentioned by image analysis can be safely used and that it is a viable and effective alternative to measure characteristics for the populations evaluated, facilitating the formation of a "pool" of information, which would be more difficult to be achieved with the use of the conventional procedures.

Estimates of variances, repeatability of the characteristics and accuracy of three evaluations

For the characters growth, diameter at breast height $(\mathrm{DBH})$, plant height $(\mathrm{H})$, cylindrical volume $(\mathrm{CV})$, stem diameter (SD), distance between nodes (internodes) and canopy diameter (CD), the repeatability estimates varied between 0.023876 and 0.269556 , as presented in Table 1, and the values for DBH (0.244188), H (0.206068) and CV (0.269556) were consistent with the magnitudes reported by Sampaio et al. (2002), in Pinus and by Garcia and Nogueira (2005) in Eucaliptus, for the same characteristics evaluated in this study.

The estimates of repeatability for the characteristic $\mathrm{CV}$ are located inside the interval of values of heritability estimates achieved by Resende (2002), between 0.14 and 0.62 , for timber volume in Eucalyptus grandis. The same author, using values found in literature, provides magnitudes of heritability averages for timber volume of 0.21 , based on 528 estimates for many forest species. It is necessary to emphasize that the values of repeatability measured for timber volume in T. ciliata, at three years of age, was 0.269556 , with value accuracy of 0.855802 , according to Table 2, revealing good perspectives of genetic gains in future breeding programs.

The most important function of heritability in genetic studies on the metric character, according to Falconer (1987), is its predictive capacity and the expression of the confidence of the phenotypic value as a guide for the genetic value. Repeatability represents the maximum value that heritability may achieve in the broad sense, because repeatability and heritability are different, since the genotypic variance used to estimate the repeatability is not only of genetic origin, but still masked by the variance components of the permanent environment and among individuals (Cruz et al., 2004). Thus, since the variance caused by the permanent envi-

Table 2 - Estimates of repeatability ( $\mathrm{r}$ ), genotypic variance (Vg), phenotypic variance (Vf), variance of the genotype $\mathrm{x}$ measurement interaction (Vgm), temporary residual variance (Ve), coefficient of determination of the effects of the genotype $\mathrm{x}$ measurement interaction (c2gm), genotypic correlation through the measurements (rgmed), accuracy in genotype selection (Acgen) for the variables diameter at breast height (DBH), plant height (H), cylindrical volume (CV), stem (SD), distance between nodes (internodes) and canopy diameter (CD).

\begin{tabular}{lccccrr}
\hline Estimate & $\mathrm{DBH}$ & $\mathrm{H}$ & $\mathrm{CV}$ & $\mathrm{SD}$ & Internodes & $\mathrm{CD}$ \\
\hline $\mathrm{Vg}$ & 0.4415 & 0.2312 & 0.0002 & 0.5865 & 1.4927 & 871.2745 \\
Vgm & 0.1465 & 0.0962 & 0.0000 & 0.2608 & 0.6013 & 4162.4537 \\
Ve & 1.2199 & 0.7945 & 0.0006 & 2.1480 & 4.9703 & 31457.6968 \\
Vf & 1.8080 & 1.1220 & 0.0009 & 2.9954 & 7.0644 & 36491.2512 \\
r & 0.2441 & 0.2060 & 0.2695 & 0.1958 & 0.2113 & 0.0238 \\
C gm & 0.0810 & 0.0857 & 0.0779 & 0.0870 & 0.0851 & 0.1140 \\
Rgmed & 0.7507 & 0.7060 & 0.7756 & 0.6922 & 0.7128 & 0.1730 \\
Acgen & 0.8398 & 0.8109 & 0.8558 & 0.8019 & 0.8153 & 0.3891 \\
General measurement & 11.8044 & 9.7176 & 0.1120 & 1.5599 & 12.1018 & 245.6525 \\
\hline
\end{tabular}


ronmental effects is minimized, repeatability becomes closer to heritability and they might even be equal, in case the estimate of the genotypic variance is exclusively of genetic nature.

As for the character DBH, works with eucalyptus, such as those developed by Rocha et al. (2007) and Martins et al. (2003), have revealed satisfactory heritability close to 0.3000. Kageyama et al. (1977) evaluated populations of Pinus patula, in two locations and achieved estimates of relative heritability for the traits $\mathrm{H}$ and $\mathrm{DBH}$, respectively, of 0.2873 and 0.1872 for a location, and 0.1623 and 0.1373 for the second location. The character $\mathrm{DBH}$ is considered the most important for the purposes of selection for wood production in E. urophylla and $E$. grandis (Rocha et al., 2007). For these species, estimates of heritability of 0.2785 and 0.2247 and accuracies of 0.61 and 0.53 , respectively for E. urophylla and E. grandis, are satisfactory for the genotype selection based on DBH (Rocha et al., 2007). Similarly, repeatability values of 0.2441 and accuracy values of 0.8398 (Table 2) are consistent references for Toona ciliata.

Height, with estimated repeatability of 0.206068 and accuracy of 0.81095 , is consistent with the interval presented by Garcia and Nogueira (2005) for the selection of clones of eucalyptus and higher than the estimates achieved by Kageyama et al. (1977), for provenances of Pinus, indicating that there are real possibilities of genetic gains in the populations of Toona ciliata evaluated.

The repeatability estimate achieved for canopy diameter (D.Canopy) of 0.023876 (Table 2) presented the lowest magnitude, indicating the highest irregularity of the superiority of the individuals among the measurements for this character. In this aspect, for ten measurements, it would be possible to achieve accuracy estimate of 0.61 . This high irregularity demonstrates that genotype selection based on this trait is not a good strategy. As for the characteristic CV, according to the Table 3, five measurements would be necessary to achieve accuracy slightly higher than 0.90 .

The estimates of the parameter accuracy for the variables diameter at breast height (DBH), plant height $(\mathrm{H})$, cylindrical volume $(\mathrm{CV})$, stem diameter $(\mathrm{SD})$ and dis- tance between nodes (Internodes) presented values ranging from 0.801902 to 0.855802 . For the canopy diameter (CD), the accuracy estimate was 0.389126 . It must be emphasized that Resende and Duarte (2007) proposed the classification of the statistical accuracy as very high (Acgen $\leq 0.90)$, high $(0.70 \leq$ Acgen $\leq 0.90)$, moderate $(0.50 \leq$ Acgen $\leq 0.70)$ and low (Acgen $\leq 0.50)$. Excepting for $\mathrm{CD}$, in this study, the accuracy estimates were high, demonstrating high accuracy in the assessment of the true genetic variation based on the phenotypic variation observed in every trait. For CD, the low accuracy was probably caused by the high environmental influence, which disqualifies this characteristic for selection procedures in Toona ciliata.

The low interaction with age, observed by the genotypic correlations during measurements (Rgmed), for the characteristics evaluated, demonstrates that selection can be performed at any of the development stages used for measurements.

The best precision in relation to the uniformity in the repetition of the character $\mathrm{CV}$ demonstrates that it is the best characteristic to be used for selection, because it expresses the best genetic control. However, since this variable is more difficult to be quantified, it can be concluded that the best option is the selection by $\mathrm{DBH}$ because it expresses high uniformity in the sequential evaluations, it is easy to quantify and presents high correlation with the character CV (Table 4). It corroborates the affirmations of Martins et al. (2003) and Sampaio et

Table 4 - Pearson correlation coefficients among the characteristics diameter at breast height (DBH), stem diameter (SD), distance between nodes (Internodes), canopy diameter (CD), height $(\mathrm{H})$ and cylindrical volume (CV).

\begin{tabular}{|c|c|c|c|c|c|c|}
\hline Variable & DBH & D.Stem & Internode & $C D$ & $\mathrm{H}$ & CV \\
\hline $\mathrm{DBH}$ & & $0.7353^{* *}$ & 0.4073 & -0.0094 & 0.2180 & $0.9391^{* *}$ \\
\hline SD & $0.7353^{* *}$ & & 0.3613 & -0.1216 & 0.0098 & $0.6383^{*}$ \\
\hline Internode & 0.4073 & 0.3613 & & -0.206 & 0.3547 & 0.4707 \\
\hline$C D$ & -0.0094 & -0.1216 & -0.2060 & & 0.3116 & 0.0896 \\
\hline $\mathrm{H}$ & 0.2180 & 0.0098 & 0.3547 & 0.3116 & & $0.5149^{*}$ \\
\hline CV & $0.9391^{* *}$ & ${ }^{*} 0.6383^{*}$ & 0.4707 & 0.0896 & $0.5149 *$ & \\
\hline
\end{tabular}

**, ${ }^{*}$, significant $1 \%$ and $5 \%$ by the $T$ test.

Table 3 - Efficiency of the use of measurements of the same individual over time for the traits diameter at breast height (DBH), height (H), cylindrical volume (CV), stem diameter (SD), distance between nodes (Internodes) and canopy diameter (CD) in Toona ciliata.

\begin{tabular}{lcccccc}
\hline \multirow{2}{*}{ measurements } & \multicolumn{5}{c}{ Accuracy } \\
\cline { 2 - 6 } $\mathrm{m}$ & $\mathrm{DBH}$ & $\mathrm{H}$ & $\mathrm{CV}$ & $\mathrm{SD}$ & Internodes & CD \\
1 & & & & & & \\
2 & 0.6662 & 0.6247 & 0.6907 & 0.6125 & 0.6308 & 0.2369 \\
3 & 0.7840 & 0.7493 & 0.8037 & 0.7386 & 0.7545 & 0.3260 \\
4 & 0.8398 & 0.8109 & 0.8558 & 0.8019 & 0.8153 & 0.3891 \\
5 & 0.8726 & 0.8480 & 0.8859 & 0.840 & 0.8518 & 0.4383 \\
6 & 0.8942 & 0.872 & 0.9056 & 0.8661 & 0.8762 & 0.4787 \\
7 & 0.9095 & 0.8907 & 0.9195 & 0.8847 & 0.8936 & 0.5128 \\
8 & 0.9209 & 0.9042 & 0.9298 & 0.8987 & 0.9068 & 0.5421 \\
9 & 0.9298 & 0.9146 & 0.9378 & 0.9097 & 0.9170 & 0.5678 \\
10 & 0.9369 & 0.9231 & 0.9441 & 0.9186 & 0.9252 & 0.5904 \\
\end{tabular}


al. (2002), who recommended selection with fulcrum in

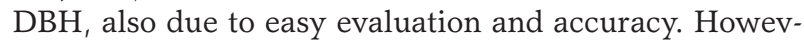
er, the most important reason is the high additive genetic correlation with height and volume.

\section{Selection and estimates of gains}

Thirty-three genotypes were selected (Table 5), out of the 90 , corresponding to $36.6 \%$ of the populations investigated for the characteristic CV. These materials presented averages higher than the general average, achieving relative performance higher than $96 \%$. The genotype 3, located in Triunfo, occupied the first position in the ranking for $\mathrm{CV}$, with genotypic value equal to 0.0373 and new average of $0.1493 \mathrm{~m}^{3}$, caused by the increase in $24.9 \%$ in the general average for the character. The genotype presenting the best ranking position for Trajano was that of the order 31, which occupied, for $\mathrm{CV}$, the fourth position in the hierarchy. Its genotypic value was 0.0347 and the new average, $0.1479 \mathrm{~m}^{3}$, re-

Table 5 - Genotype ordination for the best genetic value, average and genetic gain, for the trait cylindrical volume (CV).

\begin{tabular}{lcccccc}
\hline order & genotype & $\mathrm{g}$ & $\mathrm{u}+\mathrm{g}$ & $\begin{array}{c}\text { Genetic } \\
\text { gain }\end{array}$ & $\begin{array}{c}\text { New } \\
\text { average }\end{array}$ & u+g+gem \\
\hline 1 & 3 & 0.0373 & 0.1493 & 0.0373 & 0.1493 & 0.1529 \\
2 & 9 & 0.0366 & 0.1486 & 0.0369 & 0.1490 & 0.1521 \\
3 & 61 & 0.0349 & 0.1470 & 0.0363 & 0.1483 & 0.1503 \\
4 & 31 & 0.0347 & 0.1467 & 0.0359 & 0.1479 & 0.1501 \\
5 & 36 & 0.0328 & 0.1448 & 0.0353 & 0.1473 & 0.1480 \\
6 & 66 & 0.0293 & 0.1413 & 0.0343 & 0.1463 & 0.1441 \\
7 & 55 & 0.0150 & 0.1270 & 0.0315 & 0.1435 & 0.1285 \\
8 & 85 & 0.0130 & 0.1250 & 0.0292 & 0.1412 & 0.1262 \\
9 & 15 & 0.0127 & 0.1247 & 0.0274 & 0.1394 & 0.1260 \\
10 & 62 & 0.0102 & 0.1222 & 0.0256 & 0.1377 & 0.1232 \\
11 & 32 & 0.0101 & 0.1221 & 0.0242 & 0.1363 & 0.1231 \\
12 & 30 & 0.0095 & 0.1215 & 0.0230 & 0.1350 & 0.1224 \\
13 & 5 & 0.0089 & 0.1210 & 0.0219 & 0.1339 & 0.1218 \\
14 & 48 & 0.0089 & 0.1209 & 0.0210 & 0.1330 & 0.1218 \\
15 & 65 & 0.0085 & 0.1205 & 0.0202 & 0.1320 & 0.1214 \\
16 & 75 & 0.0074 & 0.1195 & 0.0194 & 0.1314 & 0.1202 \\
17 & 64 & 0.0062 & 0.1182 & 0.0186 & 0.1306 & 0.1188 \\
18 & 52 & 0.0056 & 0.1176 & 0.0179 & 0.1299 & 0.1181 \\
19 & 70 & 0.0051 & 0.1171 & 0.0172 & 0.1292 & 0.1176 \\
20 & 68 & 0.0051 & 0.1171 & 0.0166 & 0.1286 & 0.1176 \\
21 & 34 & 0.0045 & 0.1165 & 0.0160 & 0.1280 & 0.1170 \\
22 & 6 & 0.0037 & 0.1157 & 0.0154 & 0.1275 & 0.1161 \\
23 & 60 & 0.0037 & 0.1157 & 0.0149 & 0.1270 & 0.1160 \\
24 & 10 & 0.0036 & 0.1157 & 0.0145 & 0.1265 & 0.1160 \\
25 & 33 & 0.0032 & 0.1152 & 0.0140 & 0.1260 & 0.1155 \\
26 & 18 & 0.0031 & 0.1151 & 0.0136 & 0.1256 & 0.1154 \\
27 & 35 & 0.0027 & 0.1147 & 0.0132 & 0.1252 & 0.1150 \\
28 & 2 & 0.0025 & 0.1146 & 0.0128 & 0.1248 & 0.1148 \\
29 & 11 & 0.0024 & 0.1144 & 0.0124 & 0.1245 & 0.1146 \\
30 & 50 & 0.0012 & 0.1133 & 0.0121 & 0.1241 & 0.1134 \\
31 & 40 & 0.0007 & 0.1128 & 0.0117 & 0.1237 & 0.1128 \\
32 & 78 & 0.0005 & 0.1125 & 0.0114 & 0.1234 & 0.1125 \\
33 & 76 & 0.0004 & 0.1124 & 0.0110 & 0.1231 & 0.1125 \\
\hline & & & & &
\end{tabular}

$\mathrm{g}=$ genetic value, $\mathrm{u}=$ average, gem $=$ genetic environmental effect. vealing an increase in $24.2 \%$ in the general average. Regarding the location of Imbe, the genotype 61 stood out by achieving the best position in the ranking, occupying the third position for $\mathrm{CV}$, genotypic value of 0.0349 and new average of $0.1483 \mathrm{~m}^{3}$, characterizing an increase in $24.4 \%$ in the general average for the character. Finally, the genotype of the order 76 was the last to be selected for the characteristic $\mathrm{CV}$, and it was allocated in the $33^{\text {rd }}$ position in the ranking, with genotypic value of 0.0004 and new average of $0.1231 \mathrm{~m}^{3}$, corresponding to an increase in $9.0 \%$ in the general average for the character.

The progress expected with the selection depends on the heritability of the character, intensity of selection and phenotypic standard deviation of the character (Cruz and Carneiro, 2004). In accordance with that, the values of repeatability achieved in the present research allow the prediction of excellent possibilities of genetic gains, mainly via $\mathrm{DBH}$, by its parametric estimates higher than the height, since it is strongly related to the characteristic CV (Table 4). It allows one to infer that the selection process will also provide satisfactory results for timber volume, which is one of the most economically important characteristics for forest species.

Particularly for the characteristic timber volume, the lower correlation occurred for larger canopy diameter, with diameter at breast height. Through a global analysis, the lower correlation between two characteristics occurred between the canopy diameter and the distance between nodes (Table 4). The characteristics stem diameter (SD) and distance between nodes (Internodes) present values consistent with the values for growth characteristics.

The canopy diameter revealed that, for the genotype 5 , it is possible to achieve an increase in 21.13 $\%$ in the average, designing a new average of 311.1045 centimeters. However, there must be caution with such inference, since canopy diameter was the characteristic that expressed the lowest correlation with cylindrical volume, according to Table 4.

\section{Stability of genetic values}

The results of simultaneous genotype ordering by their genetic values (productivity) and stability, related to the genotypic stability by the harmonic mean method of the genotypic values, according to Resende (2004), found in the Tables 6 and 7, clarify the genotypic behavior through the measurements, since the lower the standard deviation, the higher the harmonic mean of its genotypic values over time.

The prediction based on the harmonic mean allows the selection by productivity and stability, simultaneously, in opposition to the procedure based on arithmetic average, which is suitable for the selection only by productivity. Thus, the selection by the criterion that employs the highest estimates of the harmonic means of the genotypic values (MHVG) is an excellent strategy, allowing safe inferences about the prediction of the genetic values, with the advantage of gathering in a single selection criterion both productivity and stability. 
Table 6 - Stability of genetic values (MHVG), for the characteristics diameter at breast height $(\mathrm{DBH})$, height $(\mathrm{H})$ and cylindrical volume (CV).

\begin{tabular}{|c|c|c|c|c|c|c|}
\hline \multirow{2}{*}{ order } & \multicolumn{6}{|c|}{ Character } \\
\hline & genotype & MHVG & genotype & MHVG & genotype & MHVG \\
\hline 1 & 9 & 13.2423 & 31 & 10.3120 & 3 & 0.1451 \\
\hline 2 & 31 & 13.1953 & 3 & 10.2226 & 9 & 0.1448 \\
\hline 3 & 66 & 13.1358 & 36 & 10.1827 & 31 & 0.1438 \\
\hline 4 & 36 & 13.1303 & 61 & 10.1059 & 61 & 0.1428 \\
\hline 5 & 61 & 13.0778 & 63 & 10.0673 & 36 & 0.1408 \\
\hline 6 & 3 & 12.9111 & 90 & 10.0287 & 66 & 0.1379 \\
\hline 7 & 85 & 12.6400 & 62 & 9.9829 & 55 & 0.1195 \\
\hline 8 & 15 & 12.6187 & 33 & 9.9778 & 15 & 0.1189 \\
\hline 9 & 32 & 12.4201 & 60 & 9.9622 & 85 & 0.1184 \\
\hline 10 & 55 & 12.3994 & 34 & 9.9161 & 32 & 0.1157 \\
\hline 11 & 75 & 12.2056 & 48 & 9.9151 & 48 & 0.1141 \\
\hline 12 & 48 & 12.1274 & 23 & 9.8839 & 62 & 0.1139 \\
\hline 13 & 18 & 12.0925 & 35 & 9.8548 & 5 & 0.1134 \\
\hline 14 & 70 & 12.0780 & 89 & 9.8397 & 75 & 0.1128 \\
\hline 15 & 5 & 12.0409 & 9 & 9.8358 & 30 & 0.1123 \\
\hline 16 & 52 & 12.0238 & 59 & 9.8315 & 65 & 0.1109 \\
\hline 17 & 68 & 12.0208 & 17 & 9.8304 & 52 & 0.1108 \\
\hline 18 & 2 & 12.0058 & 5 & 9.8290 & 70 & 0.1097 \\
\hline 19 & 10 & 11.9924 & 52 & 9.8230 & 68 & 0.1084 \\
\hline 20 & 14 & 11.9849 & 88 & 9.8190 & 34 & 0.1084 \\
\hline 21 & 73 & 11.9828 & 30 & 9.8179 & 64 & 0.1081 \\
\hline 22 & 11 & 11.9590 & 71 & 9.8167 & 10 & 0.1074 \\
\hline 23 & 76 & 11.9574 & 25 & 9.8148 & 18 & 0.1072 \\
\hline 24 & 62 & 11.9383 & 66 & 9.8090 & 60 & 0.1072 \\
\hline 25 & 6 & $11 . .8964$ & 21 & 9.7827 & 6 & 0.1066 \\
\hline 26 & 8 & 11.8779 & 29 & 9.7815 & 33 & 0.1063 \\
\hline 27 & 69 & 11.8577 & 65 & 9.7810 & 2 & 0.1063 \\
\hline 28 & 50 & 11.8497 & 16 & 9.7743 & 35 & 0.1055 \\
\hline 29 & 34 & 11.8425 & 80 & 9.7711 & 11 & 0.1053 \\
\hline 30 & 78 & 11.8360 & 55 & 9.7578 & 50 & 0.1048 \\
\hline 31 & 64 & 11.8109 & 56 & 9.7517 & 71 & 0.1041 \\
\hline 32 & 65 & 11.8026 & 54 & 9.7173 & 17 & 0.1036 \\
\hline 33 & 60 & 11.7525 & 44 & 9.7051 & 76 & 0.1029 \\
\hline
\end{tabular}

The selection of the 45 individuals ranked according to the highest genetic values is concordant in $92.10 \%$ for $\mathrm{DBH}$, in $91.11 \%$ for height and in $96.96 \%$ for cylindrical volume, with the ranking according the average components. Genotype 9 stood out for $\mathrm{DBH}$, while for $\mathrm{H}$, the 31 was the first and for $\mathrm{CV}$, the genotype 3 was the best.

The identification of genotypes with high yield and yield stability and wide adaptability to various environments is one of the main goals of forest species breeding programs; in this case the method MHVG is a breakthrough because it is based on an analysis of predicted genotypic values via a mixed model methodology (Verardi et al., 2009).

The method of mixed models (REML/BLUP) applied via the SELEGEN software system, using the BLUP procedure at individual level and repeated measures in each individual proved to be adequate to estimate the
Table 7 - Stability of genetic values (MHVG), for the characteristics stem diameter (SD), distance between nodes (internodes) and canopy diameter (D.Canopy).

\begin{tabular}{|c|c|c|c|c|c|c|}
\hline \multirow{2}{*}{ order } & \multicolumn{6}{|c|}{ Character } \\
\hline & genotype & MHVG & genotype & MHVG & genotype & MHVG \\
\hline 1 & 85 & 16.1023 & 89 & 14.3659 & 5 & 350.7697 \\
\hline 2 & 66 & 15.6169 & 63 & 14.1522 & 61 & 264.1766 \\
\hline 3 & 14 & 15.6003 & 74 & 13.6092 & 31 & 257.3581 \\
\hline 4 & 52 & 15.4751 & 59 & 13.6023 & 35 & 256.6419 \\
\hline 5 & 68 & 15.4074 & 72 & 13.5812 & 76 & 254.2714 \\
\hline 6 & 36 & 15.3843 & 19 & 13.5797 & 68 & 253.5553 \\
\hline 7 & 9 & 15.3782 & 46 & 13.5103 & 74 & 253.4823 \\
\hline 8 & 70 & 15.3648 & 66 & 13.4577 & 34 & 253.0608 \\
\hline 9 & 55 & 15.3027 & 33 & 13.4116 & 32 & 252.4194 \\
\hline 10 & 40 & 15.1854 & 32 & 13.3576 & 18 & 250.9397 \\
\hline 11 & 32 & 15.1524 & 15 & 13.3495 & 69 & 250.0714 \\
\hline 12 & 15 & 15.0589 & 80 & 13.3417 & 30 & 249.3698 \\
\hline 13 & 64 & 15.0552 & 44 & 13.2445 & 46 & 248.0189 \\
\hline 14 & 67 & 15.0157 & 28 & 13.2241 & 67 & 247.9460 \\
\hline 15 & 48 & 15.0092 & 42 & 13.2184 & 66 & 247.8256 \\
\hline 16 & 28 & 14.9853 & 26 & 13.1891 & 37 & 247.7625 \\
\hline 17 & 26 & 14.9176 & 3 & 12.9538 & 78 & 246.9891 \\
\hline 18 & 50 & 14.8963 & 62 & 12.9121 & 33 & 246.8231 \\
\hline 19 & 18 & 14.8861 & 57 & 12.9071 & 50 & 246.3116 \\
\hline 20 & 27 & 14.8760 & 36 & 12.8112 & 14 & 245.9909 \\
\hline 21 & 59 & 14.8545 & 5 & 12.6722 & 56 & 245.5374 \\
\hline 22 & 61 & 14.8064 & 1 & 12.6569 & 53 & 245.4124 \\
\hline 23 & 75 & 14.7842 & 25 & 12.6357 & 62 & 245.0744 \\
\hline 24 & 29 & 14.7280 & 50 & 12.5980 & 70 & 244.7079 \\
\hline 25 & 69 & 14.7091 & 20 & 12.5771 & 64 & 244.4918 \\
\hline 26 & 83 & 14.6988 & 22 & 12.5609 & 58 & 244.2800 \\
\hline 27 & 37 & 14.6607 & 61 & 12.5428 & 73 & 244.2194 \\
\hline 28 & 57 & 14.6501 & 76 & 12.5427 & 86 & 243.7336 \\
\hline 29 & 8 & 14.6406 & 48 & 12.4796 & 43 & 243.5996 \\
\hline 30 & 82 & 14.6339 & 2 & 12.4762 & 65 & 243.4292 \\
\hline 31 & 53 & 14.5971 & 41 & 12.4527 & 40 & 243.4207 \\
\hline 32 & 31 & 14.5517 & 51 & 12.4078 & 60 & 243.1728 \\
\hline 33 & 3 & 14.5298 & 87 & 12.3995 & 85 & 242.7503 \\
\hline
\end{tabular}

genetic parameters and predict genotypic values in situations of unbalanced data. Therefore, it is very useful and practical for Toona ciliata genetic breeding programs.

\section{References}

Cruz, C.D.; Carneiro, P.C.S. 2004. Biometric templates applied to breeding. UFV, Viçosa, MG, Brazil (in Portuguese).

Cruz, C.D.; Regazzi, A.J.; Carneiro, P.C.S. 2004. Biometric models applied to genetic improvement. 3.ed. UFV, Viçosa, MG, Brazil (in Portuguese).

Falconer, D.S. 1987. Introduction to quantitative genetics. UFV, Viçosa, MG, Brazil (in Portuguese).

Farias Neto, J.T.; Yokomizo, G.; Bianchetti, A. 2002. Genetic repeatability coeficient of caracters in peach palm. Revista Brasileira Fruticultura 24: 731-733 (in Portuguese, with abstract in English). 
Garcia, C.H.; Nogueira, M.C.S.N. 2005. The application of the reml/blup methodology for eucalypt clones selection. Scientia Forestalis 68: 107-112 (in Portuguese, with abstract in English).

Kageyama, P.Y.; Speltz, P.M.; Silva, A.P.; Ferreira, M. 1977. Genetic variation among provenances of Pinus patula Schiede and Deppe in the Telêmaco Borba-PR region. IPEF 14: 77-119 (in Portuguese).

Pinheiro, A.L.; Lani, J.L.; Couto, L. 2006. Australian cedar: growth and utilization (Toona ciliata M. Roem. Var. australis (F. Muell) Bahadur). UFV, Viçosa, MG, Brazil (in Portuguese).

Rocha, M.G.B.; Pires, I.E.; Rocha, R.B.; Xavier, A.; Cruz, C.D. 2007. Selection of Eucalyptus grandis and Eucalyptus urophylla parents for the production of interespecific hybrids using REML/BLUP and genetic diversity data. Revista Árvore 31: 977-987 (in Portuguese, with abstract in English).

Resende, M.D.V. 2002. SELEGEN-REML/BLUP: computerized genetic selection; user handbook. Embrapa Florestas, Colombo, PR, Brazil (in Portuguese).

Resende, R.M.S.; Simões, R.M.; Fernandes, J.S.C. 2000. Blup individual with repeated measures applied to breeding of perennial species. Ciência e Agrotecnologia 24: 986-997 (in Portuguese, with abstract in English).
Resende, M.D.V. 2004. Optimal statistical methods in the analysis of field experiments. Embrapa Florestas, Colombo, PR, Brazil (in Portuguese).

Resende, M.D.V.; Duarte, J.B. 2007. Precision and quality control in variety trials. Pesquisa Agropecuária Tropical 37: 182-194 (in Portuguese, with abstract in English).

Sampaio, P.T.B.; Resende, M.D.V.; Araújo, A.J. 2002. Estimates of genetic parameters and selection methods for genetic improvement of Pinus oocarpa Schiede. Pesquisa Agropecuária Brasileira 37: 625-636 (in Portuguese, with abstract in English).

Santos, G.A.; Xavier, A.; Cruz, C.D. 2006. Eucalyptus grandis progenies silvicultural performance in relation to the matrixes trees. Scientia Forestalis 70: 67-76 (in Portuguese, with abstract in English).

Verardi, C.K.; Resende, M.D.V.; Costa, R.B.; Gonçalves, P.S. 2009. Adaptability, stability and progenies selection of rubber. Pesquisa Agropecuária Brasileira 44: 1277-1282 (in Portuguese, with abstract in English). 